\title{
Comparative primate anatomy for the student
}

\author{
PRIMATE COMPARATIVE ANATOMY. Daniel L. Gebo. Baltimore: Johns Hopkins \\ University Press. 2014. 208 pp. \$84.95 (hardcover). ISBN 978-1-4214-1489-8.
}

\author{
Callum F. Ross ${ }^{1}$
}

Published online: 3 December 2016

(C) Springer Science+Business Media New York 2016

This primate comparative anatomy textbook is the best available accompaniment to an undergraduate or beginning graduate student course. Dan Gebo is not only a highly respected primate morphologist and paleontologist, specializing on the evolution of early euprimate locomotor systems, but he also has many years of experience teaching primate anatomy and evolution. As a result, the text is brief and clear, providing an excellent foundation of primate morphology that could be expanded on in accompanying lectures, depending on the level of detail required. The first few chapters include brief introductions to important concepts, such as phylogenetics, adaptation, and primate phylogeny, accompanied by a generic level survey of primate diversity. A chapter introducing very basic principles of musculoskeletal biomechanics is mostly very good: I only had minor twitches at some of the details.

The majority of the text is a review of skeletal and dental morphology in extant primates with asides on important fossils. Mat Severson has custom-designed clear, simple illustrations that mix images of behaving primates and skeletal elements as needed to explain the major features of morphological diversity and their behavioral correlates. The images are almost all very clear and nicely laid out, and minimally labelled to focus the reader. They are tightly integrated with the text, so their importance is not always obvious without actually reading, but this should not be a problem for those of us accustomed to reading more than 140 characters at a time. There is not much on anatomy of muscles or other soft tissues, with the exception of a nod to brains and a wink to eyes, but this is entirely appropriate for a textbook aimed at this market. For students that wish to chase the literature, the chapters have succinct but up to date reading lists. The book concludes with a treatment of salient aspects of great ape and human comparative anatomy that would be a great introduction to a human evolution course.

The only alternative for teachers of primate anatomy is Ankel-Simons' (2007) Primate Anatomy: An Introduction, Third Edition (Elsevier), which, compared with Gebo's book, is wordy, idiosyncratic, and less well illustrated. I highly recommend Gebo's book to teachers of undergraduate primate anatomy. The price tag for hardcover or e-book is a little steep, but the book is well bound and robust if, like me, you prefer your books to be physical objects.
Callum F. Ross

rossc@uchicago.edu

1 Department of Organismal Biology and Anatomy, University of Chicago, Chicago, IL 60637, USA 